\title{
A constituição da relação mãe-filha e o desenvolvimento dos transtornos alimentares
}

\author{
The constitution of mother-daughter relationship \\ and the development of eating disorders
}

\author{
Fabiana Elias Goulart de Andrade MOURA \\ Manoel Antônio dos SANTOS 2 \\ Rosane Pilot Pessa RIBEIRO
}

\begin{abstract}
Resumo
O presente estudo buscou compreender, por meio de abordagem qualitativa, como mães de adolescentes com transtornos alimentares vivenciaram o processo de cuidar de suas filhas desde a gestação até os dois anos de idade, procurando investigar se essas vivências relacionadas à maternidade guardam relação com o aparecimento futuro do transtorno. Foram entrevistadas seis mães de pacientes com anorexia nervosa, que estavam em seguimento ambulatorial em um serviço especializado. Os relatos maternos foram examinados pela análise de conteúdo. Os resultados evidenciaram dificuldades de sustentação (holding) por parte das mães, que acarretaram intenso sofrimento e sentimento de impotência diante das necessidades básicas das filhas. As crianças foram descritas como vorazes e insatisfeitas, sugerindo que teriam vivenciado dificuldades em assimilar o cuidado oferecido por suas mães em seus primeiros anos de vida. Desse modo, os resultados corroboram a importância de investigar as experiências infantis precoces para a compreensão da etiologia dos transtornos alimentares.
\end{abstract}

Palavras-chave: Desenvolvimento infantil; Relações mãe-filho; Transtornos de alimentação na infância; Transtornos da alimentação.

\begin{abstract}
Based on a qualitative approach, the present study aimed to understand how mothers of adolescents eating disorders with experienced the process of raising their daughters from pregnancy to their second year of age, trying to investigate the influence of those maternity experiences on the development of disorder. We interviewed mothers of six patients with anorexia nervosa who were followed up at a specialized outpatient. Maternal reports were examined by content analysis. Results showed difficulties in holding by mothers, which led to intense suffering and feeling of powerlessness in the face of the basic needs of their daughters. Children were described as voracious and unsatisfied, what suggests that they might have experienced difficulties in coping with the care offered by their mothers in their early development experiences. Thus, results corroborate the importance of investigating early childhood experiences to understand eating disorders etiology.
\end{abstract}

Keywords: Child development; Mother-child relations; Feeding and eating disorders of childhood; Eating disorders.

$\checkmark \nabla v \nabla$

1 Universidade de São Paulo, Escola de Enfermagem, Programa de Pós-Graduação Enfermagem em Saúde Pública. Av. Bandeirantes, 3900, Monte Alegre, 14040-902, Ribeirão Preto, SP, Brasil. Correspondência para/Correspondence to: R.P.P. RIBEIRO. E-mail: <rribeiro@eerp.usp.br>.

2 Universidade de São Paulo, Faculdade de Filosofia, Ciências e Letras, Programa de Pós-Graduação em Psicologia. Ribeirão Preto, SP, Brasil.

Apoio: Conselho Nacional de Desenvolvimento Científico e Tecnológico, por meio de Bolsa de Produtividade em Pesquisa concedida ao autor M.A. SANTOS 
Os Transtornos Alimentares (TA) são descritos na literatura especializada como síndromes psicossomáticas, cuja etiologia envolve fatores biológicos, genéticos, psicológicos, socioculturais e familiares (American Psychiatric Association [APA], 2006; Giordani, 2006; Morgan \& Claudino, 2005; Nilsson, Abrahamsson, Torbiornsson, \& Hägglöf, 2007; Sicchieri, Santos, Dos Santos, \& Ribeiro, 2007; Zerbe, 1993). No entanto, a compreensão tanto dos sintomas como de sua etiopatogenia ainda se reveste de um caráter enigmático e desafiador, uma vez que esses quadros contrariam o mais básico dos impulsos de vida (Andrade \& Santos, 2009).

Do ponto de vista descritivo, a Anorexia Nervosa (AN) pode ser caracterizada pela recusa em manter o peso corporal normal, medo intenso de engordar, distorção acentuada da imagem corporal, amenorreia e confusão na percepção da forma e do tamanho do corpo. Existem dois subtipos de AN: o tipo restritivo, no qual predomina uma radical restrição alimentar, havendo recusa incoercível de se alimentar, prática compulsiva de exercícios físicos, abuso de laxantes e diuréticos; e o "tipo purgativo", no qual os jejuns prolongados são quebrados por episódios de comer compulsivo, seguidos de vômitos, e também abuso de laxantes, diuréticos e prática de exercícios físicos. Já a Bulimia Nervosa (BN) pode ser caracterizada por episódios de binge eating, ou seja, surtos de ingestão maciça de alimentos, seguidos por comportamentos compensatórios de eliminação, como vômitos, uso abusivo de laxantes, diuréticos e atividade física excessiva. Os acessos incontroláveis de ingestão alimentar acarretam sentimentos de culpa, vergonha e depressão devido à perda do controle sobre o comportamento alimentar (APA, 2006).

A identificação dos fatores que podem estar associados ao aparecimento e/ou manutenção dos quadros de TA é uma questão frequentemente invocada tanto por profissionais da área da saúde (Polivy \& Herman, 2002), como pelos familiares, que buscam incessantemente respostas para a origem dos sintomas (Souza \& Santos, 2006; 2007). Entende-se que a elucidação das condições que propiciam a instalação e a manutenção desses transtornos é 234 um processo que acompanha toda a trajetória do tratamento (Bighetti et al., 2007; Kreling \& Santos, 2005; Sicchieri et al., 2007).

Os hábitos alimentares distorcidos (Dunker \& Philippi, 2003) e a imagem corporal alterada podem ser indicativos de um desajustamento mais profundo da personalidade. Nesses pacientes, o desenvolvimento do sentimento de insatisfação com o próprio corpo pode estar relacionado à expectativa de ser rejeitado pelo outro. Esse temor faria com que dependessem exageradamente da aceitação social, tornando-se, assim, mais suscetíveis às mensagens da sociedade relacionadas com a aparência física (Troisi et al., 2006). Nessa vertente, a mortificação corporal seria decorrência de uma constelação de fatores intra e intersubjetivos combinados (Fraga \& Santos, 2005) e refletiria as dificuldades de construção identitária (Scorsolini-Comin, Souza, \& Santos, 2010).

Algumas características específicas do funcionamento familiar nos TA, percebidas desde as primeiras descrições desses transtornos, atualmente vêm recebendo atenção especial e adquirindo relevância do ponto de vista etiológico. Vários são os estudos que buscam relacionar o funcionamento familiar do paciente - como fator desencadeador ou que contribui para a perpetuação do quadro -, e o desenvolvimento do TA. Determinadas características da dinâmica familiar do paciente, como baixa capacidade de expressão emocional, baixo nível de coesão e experiência de conflitos mais intensos do que nas famílias empregadas como controles, são frequentemente mencionadas pela literatura (Casper \& Troiani, 2001; Karwautz et al., 2002; Ma, 2008). A percepção dos pais e demais familiares em relação aos TA também tem chamado a atenção dos pesquisadores, como mostra estudo que tratou da correspondência entre a psicopatologia percebida pelos pais e a autorrelatada pelos adolescentes com TA (Salbach-Andrae et al., 2008). O crescente reconhecimento da relevância da implicação familiar no tratamento tem levado ao desenvolvimento de propostas de intervenção focalizadas no acolhimento dos pais (Souza \& Santos, 2009a; 2009b; 2010).

A relação mãe-filha também tem sido objeto de estudo na medida em que se caracteriza por 
predomínio de um padrão fusional e simbiótico e, ao mesmo tempo, presença de apego inseguro e nível elevado de conflito (Dupont \& Corcos, 2008). Essa ambiguidade contribui para fixar um padrão de relacionamento intenso, indiferenciado e confuso do ponto de vista da individuação (Bighetti et al., 2007). Sob essa perspectiva, o conflito estaria assentado em etapas precoces do desenvolvimento psicoafetivo, influenciado pelo modelo de cuidado materno, mais exatamente nos primórdios da relação estabelecida pela dupla. Os cuidados no início da vida incluem o processo alimentar, que constitui o primeiro elo entre mãe e filha (Fraga \& Santos, 2005).

O binômio alimentar/ser alimentado (cuidar/ ser cuidado) parece ser o primeiro grande organizador da vida psíquica do indivíduo. Considerando-se que o alimento é o organizador que baliza a relação mãe-bebê, veículo pulsional e agente de desejo, pode-se inferir a importância do processo alimentar na vida emocional da criança (Bighetti et al., 2007; Lawrence, 1991). A partir da observação clínica de crianças pequenas, Klein (1946/2006) buscou compreender as ansiedades primitivas e os sentimentos de culpa gerados pelos impulsos destrutivos e fantasias agressivas do bebê, dirigidos primeiramente ao seio da mãe, como representante de seu mundo interno, e, posteriormente, ao mundo externo - a mãe como objeto total, uma aquisição ulterior do desenvolvimento. Klein estudou os sentidos dessas manifestações do inconsciente, relacionando-as com o processo de desenvolvimento normal e também com as psicopatologias que se manifestam tanto na criança como no adulto.

Desde muito cedo, o bebê já é capaz de estabelecer o que Klein (1957/2006) denominou de relações de objeto, sendo o seio da mãe o primeiro objeto investido, com o qual estabelece uma relação de amor e ódio. A questão imperiosa para o bebê, nessa etapa precoce do desenvolvimento emocional, é como lidar com essa ambivalência. Em um primeiro momento, ocorre por parte da criança uma cisão entre um seio gratificador, que alimenta, acolhe e acalenta - o seio bom -, e outro, que provoca frustrações - o seio mau. Desse modo, a clivagem nessa etapa é um recurso primordial de defesa porque permite preservar a parte idealizada do objeto. O bebê se ocupa de defender-se contra a ansiedade aniquiladora e de reparar, na medida do possível, os danos infligidos aos objetos, primeiramente utilizando-se de mecanismos maníacos e onipotentes, para, gradualmente, conquistar maior confiança tanto em seus objetos quanto nas suas capacidades reparatórias, o que permite diminuir gradualmente a onipotência e a cisão, tornando seu ego cada vez mais coeso.

Na concepção kleiniana do desenvolvimento infantil, o bebê só se torna satisfeito quando consegue controlar suas ansiedades arcaicas. O domínio da ansiedade requer o controle da avidez, que se dá por meio da subordinação da relação alimentar a um princípio de relação de objeto (Klein, 1946/ 2006). Do ponto de vista de Klein (2006/1957), o contato com a realidade depende essencialmente do sentimento de segurança. Se a criança não está segura de receber amor, seu pleno desenvolvimento emocional ficará comprometido.

Winnicott(2000/1956) denominou de preocupação materna primária um estado psicológico especial da mãe, caracterizado por uma sensibilidade exacerbada durante a gravidez e, principalmente, no seu final, e que perdura por algumas semanas após o nascimento do bebê. Uma mãe com disponibilidade e preocupação genuína com os cuidados e necessidades de seu filho contribui para uma adaptação ativa do bebê ao ambiente externo. Winnicott afirma que, no início da vida, o bebê sente como se ele e a mãe formassem uma unidade somatopsíquica, inexistindo outra possibilidade de arranjo mental, principalmente devido à extrema dependência que a criança tem dos cuidados maternos. Para superar esse estado inicial de dependência e alcançar uma condição de relativa independência, é necessário que a mãe crie um ambiente de segurança (holding) em que a criança possa experimentar diversas sensações e experiências, sem que se sinta insegura ou ameaçada em sua integridade. Segal (1975) considera que, quando a relação é fortemente perturbada pela resposta adversa da mãe ou pela inveja do bebê - ou, normalmente, por uma combinação de ambas -, estão lançadas as bases para uma perturbação psicótica posterior. 
Bruch (1973), uma das pioneiras no estudo do TA, atribui o desenvolvimento problemático das pessoas acometidas por essas perturbações à escassez de respostas retroalimentadoras adequadas, como, por exemplo, no caso de as necessidades da criança terem sido respondidas pela mãe de modo contraditório ou com extrema solicitude, conduzindo a filha a um reconhecimento ineficaz de seus estados internos, a respostas insuficientemente diferenciadas e a deficiências conceituais ou perceptuais. A criança não receberia um retorno confirmatório de suas sensações e sentimentos, o que traria insatisfação e insegurança por não ter clareza acerca de suas próprias necessidades, dificultando, assim, o desenvolvimento de seu sentido de self. Seu sentimento de autonomia estaria prejudicado e ela se perceberia como uma mera extensão da mãe. Isso provocaria, mais tarde, um temor de se separar do convívio íntimo e da zona de influência dos pais. Assim, Bruch situa na base da comunicação mãe-filha a perturbação do comportamento alimentar, a partir de uma má organização precoce.

Na prática clínica, é bastante comum escutar relatos de mães de pacientes com TA de que suas filhas, muito antes do início dos sintomas, já apresentavam algumas características que faziam delas crianças peculiares ou diferentes das demais. Porém, as mães não sabem precisar muito bem em que consistiria essa diferença. Crianças extremamente "boazinhas", prodigiosas na escola e muito exigentes consigo mesmas aparecem invariavelmente nos relatos dessas mães, corroborando achados da literatura que descrevem as características de personalidade de pacientes com TA: pessoas perfeccionistas, com baixa autoestima, ansiedade elevada, pensamento dicotômico e incapacidade de encontrar formas adequadas de satisfação (Abreu \& Cangelli Filho, 2004; Ajuriaguerra, 1983; Lawrence, 1991; Oliveira \& Santos, 2006; Santos \& Peres, 2006). Essa recorrência discursiva motivou a proposta deste estudo de investigar, retrospectivamente, os períodos iniciais do desenvolvimento das jovens que desenvolveram TA, buscando conhecer se essas vivências guardariam relação com o aparecimento do transtorno. Apesar de existir farta teorização acerca desse aspecto, há poucos estudos empíricos que relacionam as primeiras experiências mãe-bebê ao desenvolvimento do TA. Uma exceção é o estudo de Troisi et al. (2006), que concluiu que o sentimento de insatisfação corporal em mulheres com TA está relacionado a ansiedades precoces de separação e padrão de apego inseguro.

Outro fator que motivou a proposta da presente investigação foi a constatação da escassez de estudos dedicados aos primeiros anos de vida das pacientes com AN e BN. Não são suficientemente conhecidos os eventos vitais e possíveis intercorrências perinatais que permearam a etapa inicial do desenvolvimento e que poderiam ter funcionado como estressores para a mãe e para a criança. Entretanto, o impacto das expectativas, dos desejos, dos valores e das crenças dos pais nesse período evolutivo de seus filhos também tem recebido pouca atenção da literatura especializada, o que obscurece a visão das vicissitudes da formação dos vínculos primários. Considera-se que esse conhecimento é requisito essencial não apenas do ponto de vista do seu valor diagnóstico como também de seu valor prognóstico, na medida em que contribui para o planejamento da intervenção terapêutica.

Considerando esse panorama, o objetivo do presente estudo foi compreender como as mães de adolescentes com TA vivenciaram o processo de cuidar de suas filhas desde a gestação até os dois anos de idade, buscando investigar se essas vivências guardam relação com o aparecimento do transtorno na adolescência.

\section{Método}

Estudo descritivo e interpretativo, baseado no método clínico de investigação (Triviños, 1995).

\section{Participantes}

Participaram do estudo seis mães de adolescentes. As pacientes tinham diagnóstico de TA e estavam em seguimento ambulatorial junto ao Grupo de Assistência em Transtornos Alimentares do Hospital das Clínicas da Faculdade de Medicina 
de Ribeirão Preto da Universidade de São Paulo (GRATA-HCFMRP-USP). Os critérios para inclusão no estudo foram: ser mãe de paciente com diagnóstico de AN, na faixa etária entre 10 e 20 anos, em acompanhamento no serviço no período definido pela investigação (março a agosto de 2006).

O número de participantes foi estabelecido pelo critério de saturação dos dados (Minayo, 2004). As participantes tinham entre 33 e 59 anos de idade (média de 45,5 anos, desvio-padrão de 8,3). Em relação ao grau de escolaridade, duas mães tinham ensino fundamental incompleto; três com ensino médio completo e uma com ensino superior incompleto. Quanto ao nível socioeconômico, duas participantes eram oriundas de classe média, três de classe média-baixa e uma da classe baixa. Quatro eram casadas, uma divorciada e uma solteira. O número de filhos variou de um a três. Três exerciam atividades remuneradas (comerciante, doceira e funcionária pública) e as outras três eram do lar (Tabela 1). As filhas eram solteiras e residiam com a família de origem. Todas receberam diagnóstico de AN: quatro do subtipo restritivo e duas do subtipo compulsivo/purgativo.

O serviço especializado (GRATA-HCFMRPUSP) está integrado ao Ambulatório de Nutrologia desde 1982 e adota um modelo assistencial comprometido com um olhar mais abrangente, que considera as diversas dimensões biopsicossociais envolvidas no processo saúde-doença. A equipe multiprofissional é composta por médicos nutrólogos, nutricionistas, psiquiatras, psicólogos, enfermeiros, terapeutas ocupacionais e graduandos de
Psicologia. O serviço se insere em uma instituição macro-hospitalar pública, de natureza acadêmica, que atende diferentes camadas sociais devido à sua inserção no Sistema Único de Saúde (SUS) (Bighetti et al., 2007).

\section{Procedimentos}

A estratégia metodológica escolhida para o levantamento dos dados foi a entrevista semiestruturada. Para a organização da entrevista, utilizou-se da modalidade história de vida tópica, conforme descrita por Minayo (2004), uma vez que se delimitou uma determinada etapa da vida - da gestação aos primeiros dois anos de idade da filha -, e um específico setor da experiência em questão: os cuidados maternos, particularmente com a alimentação.

As entrevistas seguiram um roteiro temático composto pela seguinte solicitação norteadora: "Conte-me tudo o que você se lembra do período desde a sua gravidez até mais ou menos dois anos de idade de sua filha", com o objetivo de favorecer as lembranças das entrevistadas. A partir daí, investigaram-se temas específicos na medida em que afloravam espontaneamente nas falas, tais como: gravidez, parto, pós-parto/puerpério, amamentação/alimentação e características da criança percebidas pela mãe.

As entrevistas foram realizadas no período de março a agosto de 2006. Foram audiogravadas com o consentimento das participantes e tiveram

Tabela 1

Caracterização das participantes do estudo. Ribeirão Preto (SP), 2007

\begin{tabular}{|c|c|c|c|c|c|c|}
\hline \multirow{2}{*}{ Caracterização } & \multicolumn{6}{|c|}{ Participantes } \\
\hline & Ana & Beatriz & Gilda & Cláudia & Dirce & Ester \\
\hline Idade & 59 & 33 & 45 & 44 & 46 & 46 \\
\hline Profissão & Do lar & Comerciante & Do lar & Doceira & Do lar & Funcionária pública \\
\hline Estado civil & Casada & Casada & Casada & Divorciada & Solteira & Casada \\
\hline Número de filhos & 2 & 1 & 3 & 2 & 2 & 2 \\
\hline Idade da filha & 18 & 10 & 19 & 17 & 17 & 20 \\
\hline Ordem de nascimento & $2^{a}$ & $1^{\mathrm{a}}$ & $1^{a}$ & $2^{a}$ & $2^{a}$ & $1^{a}$ \\
\hline Abortos anteriores & Não & Não & Sim & Sim & Não & Não \\
\hline Gravidez desejada & Sim & Sim & Sim & Não & Não & Não \\
\hline Tipo de parto & Normal & Cesárea & Cesárea & Normal & Normal & Normal \\
\hline Amamentou/período & 4 meses & 6 meses & Não & 6 meses & Não & 8 meses \\
\hline
\end{tabular}


duração média de uma hora. O corpus de análise foi constituído pela transcrição na íntegra e literal do material audiogravado. Os dados foram submetidos à análise de conteúdo e examinados de acordo com os pressupostos do método clínico de pesquisa, buscando-se a compreensão dos processos psicodinâmicos em jogo. Basicamente, foram utilizadas duas concepções teóricas para a compreensão da constituição da formação dos laços emocionais com a mãe, tendo ambas norteado a investigação: (1) a relação entre cuidados maternos e a constituição do mundo interno, incluindo fantasias e experiências emocionais, de acordo com a concepção de Klein (1946/2006; 1957/2006); (2) a mãe compreendida como ambiente, tal como proposto por Winnicott (1963/1983; 1956/2000), e suas possíveis facilidades e dificuldades em oferecer ao bebê as condições satisfatórias para seu desenvolvimento, que aqui será abordado na perspectiva dos cuidados iniciais.

O projeto foi aprovado pelo Comitê de Ética em Pesquisa do HC-FMRP-USP (Processo HCRP $\left.n^{\circ} 4967 / 2005\right)$. Foram respeitados todos os aspectos éticos envolvidos em conformidade com a Resolução n 196/96 do Ministério da Saúde. Para as mães que aceitaram participar do estudo, era apresentado o Termo de Consentimento Livre e Esclarecido e eram explicitados os objetivos do estudo, a garantia do sigilo em relação à identificação das participantes e ao conteúdo da conversa, a questão da participação voluntária (desvinculando sua participação no estudo ao tratamento da filha), a possibilidade de desistência a qualquer momento, a utilização do gravador durante a entrevista. Também eram esclarecidas eventuais dúvidas. Para preservar o anonimato das participantes, todos os nomes utilizados neste estudo são fictícios.

\section{Resultados e Discussão}

Considerando os objetivos do estudo, a análise dos dados buscou compreender os significados atribuídos pelas participantes às vivências da maternidade, segundo os temas investigados: a gravidez, o parto, o pós-parto/puerpério, o processo de amamentação/alimentação e as características da filha percebidas pelas mães.
Tendo essas dimensões como foco de análise, buscou-se organizar as falas segundo os significados destacados em cada tema. Uma vez encontrados, destacados e nomeados os significados atribuídos às vivências afetivas pelas participantes, considerou-se interessante oferecer um aprofundamento de cada tema encontrado, relacionando- o com o referencial teórico escolhido para sustentar a análise. Nesse percurso de organização do material, segmentos de falas das mães foram selecionados para ilustrar os significados atribuídos.

\section{Gravidez}

Nos relatos das participantes, a gravidez foi referida muitas vezes sob um contorno emocional intensamente ameaçador, marcado por sentimentos de angústia, medo e desamparo diante do desconhecido, especialmente no contato com suas próprias fantasias. Esse momento foi considerado muito difícil em suas vidas. Foi evocado como um período em que as dificuldades de relacionamento com o marido/companheiro, as preocupações com outros filhos e as intercorrências clínicas vivenciadas despertaram marcada ansiedade. A rejeição franca e intensa da gravidez, que acompanhou todo o período de gestação, é uma marca discursiva que perpassa os relatos:

Aí eu queria morrer, queria que ela morresse também, sabe, umas coisas assim, horrivel de pensar, né? Aí eu pensava: é melhor que ela morra, que eu morra, pensava em suicídio, pensava em que ela morresse, se eu caísse da escada, que ia acabar, sabe? Essas coisas mais tremendas foram minha gravidez (Cláudia).

Eu fiquei muito chocada quando eu fiquei grávida, porque eu não queria de jeito nenhum, eu nunca me imaginei mãe, nunca assim... Eu achava que eu não estava preparada, embora já de idade, já tinha 26 anos, mas... eu acho que eu num tava preparada pra aquilo, eu não queria ainda. Então, o fato assim, de eu achar que eu ainda tinha que fazer muita coisa pessoal, né? É... conquistar ainda muitas coisas, né? 
É... materiais, situação financeira, né? $E$, então, assim, eu fiquei chocada mesmo. Então foi uma coisa que... eu custei a aceitar, eu chorava muito, né? (Ester).

Os relatos sugerem que as mães tiveram dificuldade de aceitação emocional da gravidez, pois não se sentiam preparadas para a maternidade, além de vivenciarem outras preocupações e ansiedades concernentes à gestação da filha, que suscitaram sentimentos de frustração, raiva, medo e culpa. As lembranças das vivências depressivas que dominaram esse período de suas vidas ainda parecem carregadas de atualidade, potencializando o vazio afetivo.

Outro aspecto apontado pelas mães foi a dificuldade em lidar com o impacto emocional da gravidez sobre os outros filhos, o que parece tê-las remetido à maneira como elas próprias lidaram com situações de rejeição, exclusão e desamparo. Parecem ter encontrado dificuldades em se colocar nessa posição sem se sentirem ameaçadas pela iminência de perder o contato com seus objetos internos. Sentindo-se insegura, uma das mães não conseguiu fornecer ao filho mais velho a segurança e a tranquilidade de que ele necessitava:

Porque o Carlinhos [irmão da paciente] tinha muita dificuldade também, né? Que ele não dormia. Ele tinha dificuldade pra dormir, ele dormia um pouquinho, acordava, chorava e não dormia e aí a... aí todo mundo falava: 'Não, mas você tem que dar mais atenção pro Carlinhos, a criança nem entende, não pensa em nada, não sabe de nada enquanto é bebê'. Sabe aquelas coisas absurdas de falar, né? (Cláudia).

O luto não elaborado por abortos anteriores, que podem representar, do ponto de vista psíquico, objetos internos destruídos dentro de seu próprio corpo, pode ter comprometido a maneira como uma das mães lidou com a gravidez. Nesse caso, a nova gestação a remeteu aos conflitos com a própria agressividade e às dificuldades em manejar seus impulsos hostis: "Eu não queria ficar grávida, porque eu já tinha tido um aborto, aí eu tive o Carlinhos, depois tive dois abortos, assim de dois meses e meio... Perdi, aí eu não queria mais ficar grávida, tinha medo" (Cláudia).
O pai, por sua vez, é figura fundamental na constituição psíquica do bebê. Como objeto instalado dentro da mente da mãe, pode formar com a mãe um casal forte e criativo que organiza a vida mental do bebê (Klein, 1957/2006). Algumas mães apresentaram dificuldades em constituírem um par conjugal forte e muitas vezes mantiveram-se em uma relação de unidade fusional com sua filha, vivendo a ilusão de serem completas. Para a manutenção dessa ilusão no plano da relação dual imaginária mãe-filha, o princípio de alteridade - o terceiro representado, na tríade edípica, pela figura masculina -, tem de ser sumariamente excluído de seu funcionamento mental:
Agora eu falo pra ele [marido], assim, que eu preciso de um companheiro, mas eu não consigo também ficar dividindo com os outros, porque tudo tem que ser eu, sabe? Tudo que ele vai fazer, acho que não tá fazendo certo, aí eu já fico irritada, nervosa (Gilda).

Sentimentos de solidão e desamparo pontuam diversas falas e situações vivenciadas durante a gravidez. Para aliviar esse estado interno penoso, descrito como um vazio afetivo, as mães muitas vezes buscaram manter uma relação indiferenciada com a filha, o que remete à condição psíquica indiferenciada dos primórdios do desenvolvimento psíquico, buscando restaurar a unidade inicial perdida:

Agora na gravidez, é... a gente vivia mais sozinha, né? Eu, por exemplo, meu quarto, eu dormia, sentia muito falta de ar, sufocamento, então naquele momento eu imaginava assim, se tivesse uma pessoa do meu lado, né, pra ficar ali perto de mim, talvez não tinha sido assim, né? A gente não ficava assim com tanto medo, mas à noite, principalmente, me dava aquela angústia, aquele medo, sabe? (Dirce).

Há evidências na literatura de que o suporte emocional por parte da mãe é fator preditivo de dificuldades de vinculação em etapas posteriores do desenvolvimento. Nessa direção, Rodrigues et al. (2004) investigaram as memórias de cuidados parentais pelos pais durante a infância e sua influên- 
cia no estilo de vinculação e na qualidade das relações com pessoas significativas em adolescentes grávidas. Os resultados obtidos sugerem que a qualidade dos cuidados parentais durante a infância é um fator determinante para a qualidade da vinculação; a rejeição e a ausência de suporte emocional por parte de ambos os pais mostraram ser decisivos na emergência de estratégias inseguras de vinculação. A qualidade dos cuidados parentais recebidos durante a infância pode ter repercussões no padrão de relacionamento estabelecido com o companheiro e com a própria mãe durante a gravidez. Os cuidados parentais durante a infância também determinam a qualidade do relacionamento do indivíduo com pessoas significativas na adolescência e na vida adulta, pois contribuem para a elaboração de estratégias seguras ou inseguras de vinculação.

\section{Parto}

Ao discorrerem sobre a experiência do parto, as participantes evocaram situações de extrema ansiedade, suscitadas por complicações e intercorrências clínicas. Prematuridade, parto a fórceps, elevação da pressão arterial, anóxia neonatal, mudança de médicos e condutas médicas que elas consideraram duvidosas foram algumas das dificuldades relatadas. Essas experiências tiveram um impacto traumático no mundo psíquico dessas mães devido à insuficiência do apoio emocional recebido e/ou percebido, o que pode ter limitado as condições de processamento das emoções brutas pelo aparelho psíquico, em decorrência da fragilidade emocional por que passavam na época. Os relatos permitem inferir que a impossibilidade de elaboração psíquica deixou uma lacuna, preenchida por fantasias de aniquilamento e ansiedades persecutórias, que atuaram de maneira a potencializar os efeitos aterrorizantes dessas vivências afetivas:

Então ela teve que... não nascia, então ela foi tirada com ajuda de fórceps, então foi assim uma coisa assim chocante, acredito que tanto pra ela quanto pra mim, né? 240 (Ester).
É porque foi tudo muito tumultuado, né. Na verdade foi muito, muito, porque eles nasceram de seis meses. Eu fiquei internada por 13 dias tentando segurar, e tomando medicamento pra, pra amadurecer o pulmão, preparando o bebê pra nascer (Gilda).

Diante das dificuldades vivenciadas por essas mães durante a gestação e o parto, é possível cogitar que essas experiências podem ter influenciado a capacidade materna de oferecer um ambiente seguro para o desenvolvimento de seu bebê.

\section{Pós-parto e puerpério}

O período imediatamente após o parto também foi uma etapa muito atribulada para as mães entrevistadas. Algumas intercorrências clínicas e a vulnerabilidade física e psíquica, somadas à inexperiência com o cuidado de recém-nascidos, a sobrecarga de afazeres domésticos e o acúmulo de tarefas devido à necessidade de cuidar dos outros filhos, levaram as mães a vivenciarem estados internos disfóricos, como medo de morrer, apatia, depressão, nervosismo e ansiedade de separação. Essas vivências afetivas foram intensificadas pelo luto por perdas recentes e, principalmente, por um sentimento difuso de culpa por se sentirem negligentes e despreparadas para cuidar da filha. Tais vicissitudes afastaram as participantes de uma experiência emocional propiciadora de maior proximidade e satisfação emocional:

Minha mãe que cuidou dela. A mamãe ficou um mês comigo, porque aí eu não aguentava, eu fiquei uma semana que eu não aguentava levantar da... da cama, né, que doía tudo. Aí fui, voltei no médico, o médico deu um antibiótico fortíssimo, eu tomei, eu fiquei quase um mês, quase que eu ficava só deitada. Ea minha mãe ficava lá tomando conta dela, dava banho, minha mãe que cuidou, deu banho, deu tudo (Ana).

Comigo eu sei que [voltar ao trabalho] foi a morte pra mim... Chorava lá no trabalho, eu ia embora chorando. Muito, muito difícil mesmo. Eu num... sabe quando você não aceita aquilo de jeito nenhum e não via a 
hora que acabasse o dia pra eu ir lá buscar essa menina, né? (Ester).

A preocupação excessiva com a limpeza e a manutenção da casa parece ter funcionado como um refúgio para evadir-se de vivências emocionais dolorosas, permitindo-lhes deslocar a ansiedade decorrente do contato com seus sentimentos conflitantes. O apego obsessivo por rituais de limpeza parece ter tido a função de evitar, ou pelo menos minimizar, a intimidade com emoções desestabilizadoras. Porém, essa estratégia defensiva se mostrou pouco eficaz na medida em que gerava mais culpa e acentuava o sentimento de negligência nos cuidados dispensados à filha recém-nascida:

Hoje eu falo que é uma coisa que, nossa, se eu pudesse voltar no tempo eu também tinha deixado de lado tanta coisa, pra ficar mais com elas. Eu acho isso, assim, uma falha assim, sabe? Então eu ficava ali, que a casa tinha de ser limpa, a roupa lavada, passada, tudo na hora, aquela coisa assim, sabe? E... então ele [marido] ficava mais com ela. Então, eu acho aí que eu falhei também, sabe? Devia, né, ter deixado e ter dado assim, mais... mais carinho mesmo, né? Mais atenção. Então, isso eu acho que... que foi uma coisa que faltou da minha parte. Essa coisa ali, você sempre tinha aqueles cuidados ali, mas eu não tinha assim muita proximidade nisso (Ester).

Hoje, hoje eu vejo que, quem sabe, às vezes faltou mais alguma coisa de carinho, a gente dar mais carinho, mais atenção. Porque hoje, por exemplo, hoje eu, eu faço, eu sou voluntária na Pastoral da Criança e eu tô aprendendo, assim, como que é que você cuida de uma criança, aprendendo a ser mãe... Coisa que eu acho que faltou assim pra, pra mim. Eu, eu sinto isso, que se eu tivesse hoje um filho, trataria completamente diferente, daria mais atenção, mais carinho, brincava mais, entendeu? (Ana).

Para essas mães, maternidade e vivência de culpa parecem ter sempre andado de mãos dadas, o que contribuiu para sobrecarregar a relação precoce estabelecida com as filhas com emoções tóxicas. Experimentaram um persistente sentimento de insuficiência no desempenho do papel materno, o que complicou ainda mais um quadro permeado por muita angústia e sofrimento. Todas relataram experiências em que consideram que falharam ou que não foram suficientemente boas no que diz respeito ao cuidado de suas filhas. Juntamente com essa tendência depressiva para a autorrecriminação, sobrevém um sentimento de que foram as suas "falhas" e, consequentemente, elas próprias as possíveis responsáveis pelo aparecimento do TA nas filhas:

\begin{abstract}
Claro que ela [a filha] ia ficar com problema. Por descuido, eu acho, porque por mais que você queira cuidar, quando você está deprimida, seu cuidado é muito, muito assim... Hoje, eu me vendo hoje, naquela época, né, é muito assim, é... você não consegue nem cuidar de você, né? Você está se arrastando, como é que você vai cuidar de uma criança? Ela sofreu com isso, toda essa consequência, né? (Cláudia).
\end{abstract}

\section{Amamentação/alimentação}

A maioria das mães investigadas considerou que o apetite da filha era excessivo e suas dificuldades em corresponder a essa avidez - percebida como voracidade do bebê -, também contribuíram para incrementar sentimentos latentes de culpa e vivências de impotência:

Logo nos primeiros meses, ela tinha muito apetite, assim, ela... ela mamava muito, a cada três horas... eu acho que... me lembrando agora, eu acho que... até que hoje eu penso, né? Talvez eu tenha cometido assim, eu falo: um pecado, porque... [sorriso de constrangimento] é... é, falavam... de três em três horas, às vezes ela acordava antes, e aí eu ficava esperando, porque eu achava, então eu achava que tinha que ser ali rigorosa naquilo ali. Me lembrava que minha irmã, minha mãe, falavam, né, que logo com um mês de idade já tinha que... que tirar todas essas mamadeiras da noite pra ir acostumando, pra dormir a noite inteira. 
Então, aí, eu acho até que eu pequei um pouquinho, sabe? Eu acho que eu devia ter amamentado ela... com mais frequência, porque ela tinha fome (Ester).

A dependência absoluta na etapa inicial do desenvolvimento emocional é essencialmente positiva, pois é precursora do amor (Klein, 1957/2006). Todavia, por mais favorável que seja a orientação da criança em relação à mãe, nem por isso essa relação se encontra isenta de alguns riscos. Um dos riscos para a criança é o de que a relação possa conduzir a um estado de dependência excessiva em relação à mãe e à consequente falha no processo de constituição de seus esquemas de autonomia. Outro risco salientado por Klein é a impossibilidade de a criança suportar a solidão, devido à ansiedade persecutória e à necessidade de ser constantemente gratificada, recebendo provas de amor e benevolência que possam desmentir o temor de ser atacada e, mais tarde, abandonada (Oliveira, 2000).

No contexto do TA, podemos inferir que a voracidade das filhas possa ter sido responsável, inicialmente, por um intenso investimento no alimento. Porém, a experiência de dependência de algo tão desejado e que, em alguns momentos, mostra-se frustrante por não corresponder às expectativas pode ter gerado nas filhas sentimentos de ódio e fantasias de destruir a fonte provedora (o seio), e ter acentuado a ansiedade persecutória, visto que o objeto parcial também é muito amado. Como resposta a esses sentimentos conflitivos e ambivalentes, pode-se recorrer à desvitalização do alimento, como representante direto da experiência emocional com a mãe. Há, por conseguinte, uma diminuição dos afetos positivos que permitem a identificação com os aspectos gratificantes do objeto. Esse processo permite a negação da própria voracidade e dependência do objeto, mas, por outro lado, compromete a formação dos laços emocionais com os pais.

O risco de dependência excessiva e adesiva em relação ao objeto materno, no entanto, para Klein (1957/2006), é menor do que o do lactente ávido, que pode aparentar ser mais independente das perturbações do meio, mas que está já em vias

242 de deformar o seu ego e de se mutilar de maneira irreversível, fechando-se para o objeto, a fim de investir apenas na sua própria satisfação (Oliveira, 2000; Petot, 1987).

O desmame é um período complexo e necessário também do ponto de vista do desenvolvimento emocional da criança. É um importante passo no processo de individuação do bebê. Para as mães participantes do presente estudo, as vicissitudes experimentadas no manejo do desmame fornecem alguns indícios de como seus bebês vivenciaram esse período:

\begin{abstract}
A amamentação foi até dois anos e meio. Mamou bastante. Portanto, nesse tempo que ela mamou, não pegava uma gripe, um resfriado, nada. Só o peito também, não tomava outro leite não. O peito e comia, né? [...] Ela era muito apegada, né? Porque o peito é muito... a criança fica muito apegada com a mãe, né? Em 97, porque ela nasceu em 95, em 97, no meio do ano, eu precisei fazer uma cirurgia, foi aí que eu tirei ela... do peito. Mas assim, eu deixei ela uns dois dias sem, passou um dia, eu falei: 'Ela não pediu, né?' Quando ela vinha assim, sabe? Com manha assim, eu saía de perto, fazia outra coisa, conversava outra coisa com ela. Só que, assim, aí, ao mesmo tempo em que eu fiz a cirurgia, ela ficou com a minha mãe, aí que ela sentiu a minha falta, sabe? Isso também mexeu muito com ela. E eu não podia... Não foi, nunca foi uma criança, assim, que eu pude pegar no colo, até essa idade aí eu pegava, e depois de dois anos e meio eu nunca mais peguei ela (Beatriz).
\end{abstract}

Das sete mães estudadas, duas consideraram que os processos de amamentação e desmame foram tranquilos; duas não amamentaram suas filhas (uma alegou o fato de o bebê ser prematuro, e a outra alegou que não tinha leite) e duas consideraram o desmame difícil: Ester considerou-o precoce, devido à necessidade de voltar ao trabalho, e Beatriz, apesar de considerar que o momento era adequado, precisou proceder ao desmame não por vontade própria, mas por conta de uma cirurgia a que se submeteu. Esses dados corroboram a literatura, que aborda a dificuldade dessas mães em alimentar suas filhas (Bruch, 1973). No entanto, 
todas as mães consideraram que a introdução de novos alimentos foi normal, no tempo indicado pelo pediatra, com sucos ou chás entre três e cinco meses. Relataram que as crianças foram gradativamente assimilando os alimentos sólidos:

Ela comia normalmente. Aquela quantidade... pouquinha, mas comia normalmente, no almoço, na janta. Tinha certas coisas que ela não gostava, refrigerante ela não gostava, muitas coisas assim ela não gostava, sabe? Mas com o passar do tempo foi crescendo, ai ela foi comendo, mas toda vida ela comeu, assim, normal, a comida (Cláudia).

Em sintonia com as percepções maternas acerca das dificuldades e dos sentimentos ambivalentes enfrentados no período de amamentação, para a criança, uma ruptura abrupta do contato com o seio materno pode ter vindo acompanhada de fantasias de que ela, de fato, representava ameaça à integridade do objeto. Fantasias persecutórias dessa natureza podem ter sido capazes de conduzir as crianças, que atualmente são adolescentes diagnosticadas com AN, a uma busca incessante pela confirmação de que não foram responsáveis pela destruição do objeto amado. Essa pode ser uma busca de reparação malsucedida, que se arrasta por toda a vida.

Rapoport e Piccinini (2011) mostraram que, no primeiro ano de vida do bebê, as mães apresentam maior solicitação de apoio social durante as diversas situações estressantes que vivenciam; quando ele é recebido, sentem que isso as auxilia tanto do ponto de vista emocional como prático. No presente estudo, os relatos maternos sugerem que as participantes se sentiram sobrecarregadas nos primeiros meses de vida das filhas, porém se consideraram as grandes responsáveis pelas falhas de maternagem. Não valorizaram o fato de que o desgaste físico e emocional da maternidade poderia ter sido atenuado caso tivessem recebido suporte de seus companheiros na divisão das tarefas.

\section{Características psicológicas da filha}

As participantes descreveram suas filhas como crianças extremamente dóceis, amistosas e "boazinhas" nos primeiros meses de vida. Segundo os depoimentos, eram bebês que exigiam muito pouco de suas cuidadoras:

\begin{abstract}
Ah, a Carolina era um anjinho, um amorzinho, né? Porque ela era calminha, tranquila, ela mamava, eu trocava ela, conversava um pouquinho com ela, ela dormia, sabe? Um anjo! E aí a Carolina foi ficando cada vez mais, então, mais... E então a Carolina foi se tornando uma criança assim, ela foi crescendo e... muito, com muita autonomia, entende? Ela... logo, até os quatro meses a Carolina era um santo mesmo, ela só mamava e dormia, ficava na cama, não dava trabalho nenhum, era uma coisinha assim... (Cláudia).
\end{abstract}

Esse excerto sugere uma concepção de "filha boazinha". Considerando as dificuldades apresentadas pelas mães de se dedicarem aos cuidados de seus bebês, talvez esse estado interpretado por elas como evidência de que as filhas eram "excessivamente boazinhas" possa ter sido uma resposta emocional da filha em relação a um sentimento intenso de desamparo, levando a uma desistência de se apresentar para a mãe com suas necessidades básicas que ansiavam ser preenchidas. No lugar do cuidado que não vem, a criança passa, então, a alucinar a gratificação proporcionada pelo objeto e a não mais contar com ele, tornando-se cada vez mais autônoma, denegando, desse modo, a dependência inerente à sua situação de imaturidade.

Este estudo permitiu compreender como as mães experienciaram o processo de cuidar de suas filhas desde a gestação até os dois anos de idade. Pela análise das entrevistas e das impressões captadas pela pesquisadora a partir do contato com as mães, conclui-se que essas participantes tiveram muita dificuldade em vivenciar o que Winnicott (1956/2000) denominou de preocupação materna primária. Pode-se conjecturar que isso decorreu de falhas em sua constituição da maternagem, possivelmente por elas próprias não terem se sentido suficientemente acolhidas em suas experiências primárias com seus objetos, o que pode ter acarretado prejuízos na constituição dos laços emocionais estabelecidos com seus cuidadores. 
Os resultados evidenciaram que, desde a gravidez, as mães se mostraram insatisfeitas com a maternidade. Após o nascimento do bebê, elas sentiram dificuldades de holding (Winnicott, 2000/ 1956) que acarretaram intenso sofrimento e sentimento de impotência diante das necessidades básicas das filhas. Os bebês foram descritos como vorazes e insatisfeitos, sugerindo que, por sua parte, também teriam vivenciado dificuldades em assimilar o cuidado oferecido por suas mães. As mudanças vividas nesse período apresentam particularidades que guardam relação com as alterações do comportamento alimentar surgidas no desenvolvimento ulterior da criança. Os sentimentos relacionados à maternagem foram permeados por medo e desamparo, contaminados por fantasias de ser uma cuidadora inepta e insuficiente.

Os relatos maternos também remetem a uma suposição de que, para as mães, assim como para suas filhas, o ambiente não foi significado como acolhedor e favorável ao desenvolvimento emocional primário. Foram evocadas vivências de extrema angústia e solidão e em nenhum momento as participantes conseguiram recordar ou valorizar alguma experiência de acolhimento ou sentimento de terem sido amparadas durante a gravidez. O nascimento de suas filhas foi sentido, mais do que como uma separação, como uma ruptura na linha de continuidade de seu existir, que teve uma ressonância traumática que não pôde ser posteriormente mitigada e elaborada, e da qual o ego emergiu mutilado e fragilizado. A marca de irremediado desamparo pontuou os relatos que, das experiências vividas, priorizaram aquelas configuradas como dolorosas, ameaçadoras e afetivamente empobrecidas, marcando os primeiros estágios de convivência com a filha.

O parto difícil representa também a dificuldade em se desligar do sentimento de estar acompanhada, a perda insuportável do sentido de unidade advinda da presença de um ser até então abrigado em seu útero e a consequente necessidade de restauração desse elo perdido com o objeto. A relação estabelecida com o bebê foi permeada de vivências de impotência e culpa, em decorrência necessidades das filhas, bem como de acolher amorosamente suas próprias demandas afetivas, expectativas e angústias. Nesse contexto, prevalece o cuidado diário que preenche as necessidades físicas da criança, mas que permanece pouco atento às suas necessidades de desenvolvimento afetivo.

Entretanto, nos relatos maternos, também se constatou que as filhas parecem ter captado inconscientemente as limitações emocionais das mães e passaram a se comportar como se não dependessem de seus cuidados. Desde uma etapa precoce do desenvolvimento, buscaram uma forma compensatória de autonomia, criando um mundo interno baseado provavelmente na fuga da realidade, tornando-se bebês extremamente dóceis, submissos e que não exigiam de suas mães o cuidado materno, sequer o suprimento das necessidades elementares de sobrevivência física. Eis o segredo das filhas "boazinhas" que se tornariam adolescentes perfeccionistas até o ponto de emergência dos sintomas que se manifestam, não por acaso, na recusa alimentar. Não que não desejassem realmente ser cuidadas: pelo contrário, segundo a maioria dos relatos maternos, as filhas apresentaram-se como crianças vorazes e ávidas ao contato com a mãe. Pode-se conjecturar que apenas buscavam amortecer a consciência da insuficiência de provisões maternas, de modo a evitar o sofrimento e a se proteger de sentimentos catastróficos potencializados pela escassez de provimento afetivo.

Essas vivências inominadas, como não podem ser traduzidas psiquicamente, aparecem como vazio, que ocupa o espaço psíquico com o excesso de angústia não metabolizada, expressa como transbordamento de necessidades afetivas incontidas. Dessa maneira, estariam lançadas as bases para a futura psicopatologia do TA, caracterizada por uma dinâmica peculiar em que um onipresente sentimento de vazio interno convive com uma permanente ameaça de descontrole, de transbordamento dos impulsos. Assim, uma vez instalada a psicopatologia, essas pacientes alternam entre uma espécie de horror ao vazio e um sentimento de falsa plenitude (Santos, Oliveira, Moscheta, Ribeiro, \& Santos, 2004), decorrente de uma vivência arcaica de fusão - vivência que é recusada pela mega- 
lomania -, e de uma rejeição do corpo (assim como das experiências pulsionais) que essa recusa exige (Ajuriaguerra, 1983). Instala-se, assim, uma dinâmica intrapsíquica que alterna polaridades que não podem ser integradas: o cheio e o vazio, o controle maníaco (dos impulsos e do objeto de satisfação) e o descontrole, o ascetismo e o desregramento (Santos, 2006).

É interessante relacionar essas hipóteses com a tendência de pacientes com AN a apresentarem comportamento submisso e empobrecimento em termos de habilidades sociais, de acordo com a literatura (Connan, Troop, Landau, Campbell, \& Treasure, 2007). A pseudomaturidade constitui uma característica saliente nesses quadros (Bruch, 1973). Os resultados corroboram ainda achados obtidos por outros estudos que focalizaram os problemas precoces do desenvolvimento emocional (Dupont \& Corcos, 2008; Troisi et al., 2006).

A descrição que as mães teceram sobre os primeiros anos de vida de suas filhas chama mais a atenção para necessidades e dificuldades das próprias depoentes do que propriamente para questões emocionais de suas filhas. Segundo Selvini-Palazzoli (1978), a anoréxica é submetida às necessidades da mãe. Como mencionado, as filhas foram descritas ora como bebês vorazes e insatisfeitos, ora como bem adaptados, calmos e tranquilos, a despeito do universo emocional turbulento vivenciado pelas mães. Pode-se perceber que as filhas foram pouco percebidas em suas necessidades específicas, pouco vistas como pessoas que davam seus primeiros passos na vida e, talvez, pouco confirmadas em sua existência. Como seres não reconhecidos em sua existência própria, pacientes com AN evidenciam acentuada fragilidade egóica, são propensas à utilização de mecanismos arcaicos de defesa, caracterizam-se por uma restrição do potencial adaptativo, controlam os próprios impulsos com excessivo rigor e tendem à passividade, introversão, obsessão e dependência (Connan Troop et al., 2007; Santos \& Peres, 2006; Peres \& Santos, 2011).

Os resultados oferecem apoio empírico que reforça a hipótese de que perturbações precoces da relação mãe-criança parecem ser acentuadas nos transtornos graves do comportamento alimentar. Nesse sentido, os achados convergem para os estudos que sugerem que o sintoma alimentar pode ser considerado uma tentativa da filha de retomar a relação de objeto complexa e sofrida, a partir de uma equação simbólica na qual o alimento/objeto materno, tão investido e desejado, torna-se tóxico e por isso deve ser tenazmente evitado ou eliminado. Não se pode viver com, nem se pode viver sem. Eis o paradoxo da anoréxica.

A suposição que pode ser esboçada é a de que houve, no caso das duplas constituídas por mães e filhas que foram delineadas pelos discursos das participantes, um encontro dramático entre uma criança extremamente voraz, com sérias dificuldades em lidar com seus intensos impulsos destrutivos, e sua mãe, que, por dificuldades próprias de lidar com seus sentimentos e vivências mais primárias, não pôde oferecer a continência necessária para aplacar os sentimentos de terror e desvalia da filha. O que se sucede são as tentativas frustradas da filha, via formação sintomática, de se haver com essas vivências iniciais que não puderam ser elaboradas e simbolizadas desde as primeiras relações.

O sintoma alimentar pode ser entendido, portanto, como uma tentativa malsucedida da filha de resgatar sua experiência emocional com a mãe, buscando dimensionar o mal que julga lhe ter causado ou certificando-se de que não a destruiu nem destruiu a relação afetiva. O alimento torna-se, então, objeto envenenado pela voracidade e persecutoriedade, e como tal deve ser sistematicamente evitado, como no caso da AN, ou sumariamente expelido, como na AN do tipo purgativo e na BN. A comida, mais do que representante do desvelo da mãe, converte-se na ameaça concreta de que seus maus sentimentos se voltem contra ela própria. Nesse contexto, a capacidade simbólica da filha fica comprometida, prejudicando os esforços de reparação do ego danificado. Desse modo, tanto a paciente como a mãe veem-se mergulhadas e indiferenciadas em uma intrincada rede em que as relações afetivas adquirem um contorno emocional intenso e por vezes bastante ameaçador ao princípio de integridade corpórea que sustenta a identidade. 
Entretanto, é preciso ter cautela na interpretação dos dados para não culpabilizar essas mães pelo TA desenvolvido por suas filhas, visto que são diversos os fatores possivelmente envolvidos na etiologia desses quadros. A falta de apoio vivenciado por essas mulheres nos momentos tão cruciais do desenvolvimento de suas filhas é um elemento importante que ajuda a compreender suas vivências de desamparo, porém também se deve ter cuidado para não atribuir a responsabilidade inteiramente às filhas, por exemplo, quando se conjectura que teriam sido bebês vorazes e insaciáveis. Desse modo, a questão da suposta "voracidade" presente nesses bebês precisa ser matizada. Teriam sido esses bebês tão vorazes ou suas mães os perceberiam assim? Uma das vinhetas apresentadas sugere a ideia de que a mãe não teria sabido como alimentar seu bebê, em função de sua dificuldade em lidar com as orientações recebidas, e não porque se deparou com uma suposta voracidade da criança. Seria interessante que estudos futuros se dedicassem a investigar essa questão, de modo a contribuir para o avanço do conhecimento sobre a influência dos aspectos relacionais - particularmente no que concerne à relação mãe-criança -, na etiologia da AN.

\section{Referências}

American Psychiatric Association. (2006). Practice guideline for the treatment of patients with eating disorders ( $3^{\text {th }}$ ed.). Washington, DC: Author.

Andrade, T. F., \& Santos, M. A. (2009). A experiência corporal de um adolescente com transtorno alimentar. Revista Latino-Americana de Psicopatologia Fundamental, 12(3), 454-468.

Abreu, C. N., \& Cangelli Filho, R. (2004). Anorexia nervosa e bulimia nervosa: abordagem cognitiva-construtivista de psicoterapia. Revista de Psiquiatria Clínica, 31(4), 177-183.

Ajuriaguerra, J. (1983). A esfera oroalimentar (sua organização e seus distúrbios). In J. Ajuriaguerra. Manual de psicopatologia infantil (pp.175-208). São Paulo: Masson.

Bighetti, F., Santos, M. A., Ribeiro, R. P. P., Oliveira, E. A., Unamuno, M. R. D. L., \& Dos Santos, J. E. (2007). Transtornos alimentares: anorexia e bulimia nervosas. In C. E. Kalinowski (Org.), PROENF - Programas de Atualização em Enfermagem: saúde do adulto (pp.9-44).
Bruch, H. (1973). Eating desorders: Obesity, anorexia nervosa and the person within. New York: Basic Books.

Casper, R., \& Troiani, M. (2001). Family functioning in anorexia nervosa differs by subtype. International Journal of Eating Disorders, 30(3), 338-342.

Connan, F., Troop, N., Landau, S., Campbell, I., \& Treasure, J. (2007). Poor social comparison and the tendency to submissive behavior in anorexia nervosa. International Journal of Eating Disorders, 40(8), 733-739.

Dunker, K. L. L., \& Philippi, S. T. (2003). Hábitos e comportamentos alimentares de adolescentes com sintomas de anorexia nervosa. Revista de Nutrição, 16(1), 51-60. http://dx.doi.org/10.1590/S1415-5273200 3000100006

Dupont, M. E. \& Corcos, M. (2008). Aspects psychopathologiques des troubles des conduites alimentaires. La Revue du Praticien, 58(2), 141-149.

Fraga, L. B., \& Santos, M. A. (2005). A mortificação do corpo na anorexia nervosa: considerações sobre a função de holding na psicoterapia. In M. A. Santos, C. P. Simon, \& L. L. Melo-Silva (Orgs.), Formação em Psicologia: processos clínicos (pp.163-184). São Paulo: Vetor.

Giordani, R. C. F. (2006). A autoimagem corporal na anorexia nervosa: uma abordagem sociológica. Psicologia \& Sociedade, 18(2), 81-88.

Karwautz, A., Haidvogl, M., Wagner, G., Nobis, G., Wober-bingol, C., \& Friedrich, M. H. (2002). Subjective family image in anorexia nervosa and bulimia nervosa in adolescence: A controlled study. Z Kinder und Jungendpsychiatrischer Psychotherapy, 30(4), 251-259.

Klein, M. (2006). Notas sobre alguns mecanismos esquizóides. In Inveja e gratidão e outros trabalhos (1946-1963) (pp.17-43). Rio de Janeiro: Imago. (Originalmente publicado em 1946).

Klein, M. (2006) Inveja e gratidão. In Inveja e gratidão e outros trabalhos (1946-1963) (pp.205-267). Rio de Janeiro: Imago. (Originalmente publicado em 1957).

Kreling, D. B., \& Santos, M. A. (2005). Anorexia nervosa: um relato de atendimento clínico realizado em contexto multidisciplinar. In M. A. Santos, C. P. Simon, \& L. L. Melo-Silva (Orgs.), Formação em psicologia: processos clínicos (pp.143-161). São Paulo: Vetor.

Lawrence, M. (1991). A experiência anoréxica. São Paulo: Summus.

Ma, J. L. (2008). Eating disorders, parent-child conflicts, and family therapy in Shenzhen, China. Quality Health Research, 18(6), 803-810.

Minayo, M.C. (2004). O desafio do conhecimento científico: pesquisa qualitativa em saúde ( $8^{\mathrm{a}}$ ed.). São Paulo: Hucitec.

Morgan, C. M., \& Claudino, A. M. (2005). Epidemiologia e etiologia. In C. M. Morgan \& Claudino (Orgs.), Guia de transtornos alimentares e obesidade. Barueri: Manole. 
Nilsson, K., Abrahamsson, E., Torbiornsson, A., \& Hägglöf, B. (2007). Causes of adolescent onset anorexia nervosa: Patient perspectives. Eating Disorders, 15(1), 125-133.

Oliveira, E. A., \& Santos, M. A. (2006). Perfil psicológico de pacientes com anorexia e bulimia nervosas: a ótica do psicodiganóstico. Medicina (Ribeirão Preto), 39(3), 353-360.

Oliveira, R. A. (2000). Do vínculo às relações sociais: aspectos psicodinâmicos. Análise Psicológica, 18(2), 157-170.

Peres, R. S., \& Santos, M. A. (2011). Técnicas projetivas na avaliação de aspectos psicopatológicos da anorexia e bulimia. Psico - USF, 16(2), 185-192.

Petot, J. M. (1987). Melanie Klein I: primeiras descobertas e primeiro sistema 1919-1932. São Paulo: Perspectiva.

Polivy, J., \& Herman, C. P. (2002). Causes of eating disorders. Annual Review of Psychology, 53(1), 187213.

Rapoport, A., \& Piccinini, C. A. (2011). Maternidade e situações estressantes no primeiro ano de vida do bebê. Psico - USF, 16(2), 215-225.

Rodrigues, A., Figueiredo, B., Pacheco, A., Costa, R., Cabeleira, C., \& Magarinho, R. (2004). Memória de cuidados na infância, estilo de vinculação e qualidade da relação com pessoas significativas: estudo com grávidas adolescentes. Análise Psicológica, 22(4), 643-665.

Salbach-Andrae, H., Klinkowshi, N., Lenz, K., Pfeiffer, E., Lehmkuhl, U., \& Ehrlich, S. (2008). Correspondence between self-reported and parent-reported psychopathology in adolescents with eating disorders. Psychopathology, 41(5), 307-312.

Santos, M. A. (2006). Sofrimento e esperança: grupo de pacientes com anorexia e bulimia nervosas. Medicina, 39(3), 386-402.

Santos, M. A., Oliveira, E. A., Moscheta, M. S., Ribeiro, R. P. P., \& Dos Santos, J. E. (2004). "Mulheres plenas de vazio": os aspectos familiares da anorexia nervosa. Vínculo, 1(1), 46-51.

Santos, M. A., \& Peres, R. S. (2006). Contribuições do desenho da figura humana para avaliação da imagem corporal na anorexia nervosa. Medicina, 3(39), 361-370.

Segal, H. (1975). Introdução à obra de Melanie Klein. Rio de Janeiro: Imago.

Selvini-Palazzoli, M. (1978). Self-starvation: From individual to family therapy in the treatment of anorexia nervosa. New York: Jason Aronson.

Sicchieri, J. M. F., Santos, M. A., Dos Santos, J. E., \& Ribeiro, R. P. P. (2007). Avaliação nutricional de porta- dores de transtornos alimentares: resultados após a alta hospitalar. Ciência, Cuidado e Saúde, 6(1), 68-75.

Souza, L. V., \& Santos, M. A. (2006). A família e os transtornos alimentares. Medicina, 39(3), 403-409.

Souza, L. V., \& Santos, M. A. (2007). Anorexia e bulimia: conversando com as famílias. São Paulo: Vetor.

Souza, L. V., \& Santos, M. A. (2009a). A construção social de um grupo multifamiliar no tratamento dos transtornos alimentares. Psicologia: Reflexão e Crítica, 22(3), 317-326.

Souza, L. V., \& Santos, M. A. (2009b). A construção de sentidos em um grupo de apoio aos familiares de pessoas com transtornos alimentares. In: S. R. Pasian, G. Romanelli, \& M. V. Cunha (Orgs.), Investigação científica em psicologia: aplicações atuais em saúde (pp.69-84). São Paulo: Vetor.

Souza, L. V., \& Santos, M. A. (2010). A participação da família no tratamento dos transtornos alimentares. Psicologia em Estudo, 15(2), 285-294.

Scorsolini-Comin, F., Souza, L. V., \& Santos, M. A. (2010). A construção de si em um grupo de apoio para pessoas com transtornos alimentares. Estudos de Psicologia (Campinas), 27(4), 467-478. http://dx.doi.org/10.15 90/S0103-166X2010000400005

Triviños, A. N. S. (1995). Introdução à pesquisa em ciências sociais: a pesquisa qualitativa em educação: o positivismo, a fenomenologia, o marxismo. São Paulo: Atlas.

Troise, A., Di Lorenzo, G., Alcini, S., Nanni, R. C., Di Pasquale, C., \& Siracusano, A. (2006). Body dissatisfaction in women with eating disorders: Relationship to early separation anxiety and insecure attachment. Psychosomatic Medicine, 68(1), 449-453.

Winnicott, D. W. (1983). O desenvolvimento da capacidade de se preocupar. In D. W. Winnicott. O ambiente e os processos de maturação: estudos sobre a teoria do desenvolvimento emocional (pp.70-78). Porto Alegre: Artes Médicas. (Originalmente publicado em 1963).

Winnicott, D. W. (2000). A preocupação materna primária. In D. W. Winnicott. Da pediatria à psicanálise: obras escolhidas (pp.399-405). Rio de Janeiro: Imago. (Originalmente publicado em 1956).

Zerbe, K. J. (1993). Whose body is it anyway?: Understanding and treating psychosomatic aspects of eating disorders. Bulletin of Menninger Clinic, 57, 319-327.

Recebido: fevereiro 20, 2009

Versão final: fevereiro 3, 2012

Aprovado: fevereiro 16, 2012 
